\title{
Erratum to: Site Specific Delivery of Microencapsulated Fish Oil to the Gastrointestinal Tract of the Rat
}

Glen S. Patten • Mary Ann Augustin •

Luz Sanguansri $\cdot$ Richard J. Head $\cdot$

Mahinda Y. Abeywardena

Published online: 24 February 2011

(C) Springer Science+Business Media, LLC 2011

Erratum to: Dig Dis Sci (2009) 54:511-521

DOI 10.1007/s10620-008-0379-7

The original article was erroneously published as "The rats were denied food for a further 4,9 or $14 \mathrm{~h}$ after gavage" instead of "The rats were allowed food for a further 4, 9 or $14 \mathrm{~h}$ after gavage". The correct sentence is given below:

The rats were allowed food for a further 4,9 or $14 \mathrm{~h}$ after gavage and were anaesthetized by sodium pentobarbitone (80 mg/kg, i.p.).

The online version of the original article can be found under doi:10.1007/s10620-008-0379-7.

G. S. Patten $(\bowtie) \cdot$ M. Y. Abeywardena CSIRO Human Nutrition, P.O. Box 10041, Adelaide BC, SA 5000, Australia

e-mail: glen.patten@csiro.au

M. A. Augustin · L. Sanguansri

Food Science Australia, Werribee, VIC, Australia

R. J. Head

CSIRO Preventative Health National Research Flagship,

Adelaide, SA, Australia 